\title{
EVALUATION OF ANTIOXIDANT POTENTIAL AND QUANTITATIVE ESTIMATION OF PHENOLIC AND FLAVONOID CONTENT IN SOME SELECTED NEPALESE MEDICINAL PLANTS
}

\author{
RUPAK KHAREL, KHAGA RAJ SHARMA*
}

Central Department of Chemistry, Tribhuvan University, Kirtipur, Kathmandu, Nepal. Email: khagaraj_sharma33@yahoo.com

Received: 25 October 2019, Revised and Accepted: 18 November 2019

\begin{abstract}
Objective: The aim of this study is to evaluate the antioxidant potential, determination of total phenolic and flavonoid content in nine selected medicinal plants Spondias pinnata, Melia azedarach, Ageratina adenophora, Urtica dioica, Curcuma longa, Bauhinia variegata, Elaeocarpus angustifolius Blume, Achyranthes aspera, and Psidium guajava from Kavre district of Nepal using in vitro studies.
\end{abstract}

Methods: Methanolic plant extracts were prepared by cold percolation method. The methanol extract of nine medicinal plants collected from Kavre district of Nepal, was screened for assessing bioactive phytoconstituents followed by antioxidant property, total phenolic, and flavonoid content. Different plants collected were powdered and extracted with methanol, concentrated by a rotatory evaporator and analyzed for the presence of phytochemicals. The antioxidant potential of the plant extracts was evaluated by 2,2-diphenyl-1-picrylhydrazyl (DPPH) radical scavenging assay.

Results: The phytochemical analysis of methanolic extracts of all nine medicinal plants displayed the presence of various secondary metabolites such as alkaloids, flavonoids, polyphenols, saponins, and quinones. The extract of $S$. pinnata showed the highest percentage of radical scavenging activity up to $87.94 \pm 1.88$ with $50 \%$ inhibitory concentration $\left(\mathrm{IC}_{50}\right) 17.51 \pm 1.27 \mu \mathrm{g} / \mathrm{mL}$, followed by $B$. variegata, $80.63 \pm 1.06$ with $\mathrm{IC}_{50}$ value $26.55 \pm 2.61 \mu \mathrm{g} / \mathrm{mL}$. The standard, ascorbic acid has $\mathrm{IC}_{50}$ value of $20.13 \pm 1.17 \mu \mathrm{g} / \mathrm{mL}$. Further, the ethyl acetate fraction of $S$. pinnata showed the maximum percentage of radical scavenging (85.92 \pm 1.37 ) with IC ${ }_{50}$ value of $46.95 \pm 1.17 \mu \mathrm{g} / \mathrm{mL}$. Moreover, S. pinnata displayed the highest total phenolic content (TPC) $48.26 \pm 1.23 \mathrm{mg}$ GAE/g (milligram gallic acid equivalent per gram) extract while the highest flavonoid content was displayed by Melia azedarach $41.07 \pm 1.53 \mathrm{mg} \mathrm{QE} / \mathrm{g}$ (milligram quercetin equivalent per gram) extract measured by the Folin-Ciocalteu reagent method and aluminum chloride colorimetric method.

Conclusions: The preliminary results of this study have put forward the extract of $S$. pinnata showed the highest percentage of radical scavenging activity and S. pinnata displayed the highest TPC while the highest flavonoid content was displayed by Melia azedarach methanolic extracts although the further studies are needed to assess its mechanism of action.

Keywords: Antioxidant, Total phenolic content, Total flavonoid content, Phytochemicals.

(C) 2020 The Authors. Published by Innovare Academic Sciences Pvt Ltd. This is an open access article under the CC BY license (http://creativecommons. org/licenses/by/4. 0/) DOI: http://dx.doi.org/10.22159/ajpcr.2020.v13i1.36182

\section{INTRODUCTION}

Due to its greatly varied geographical and climatic conditions of Nepal, there is huge biodiversity of plants with medicinal and aromatic values. Nepal, being located at the portion of Central Himalayas, has contributed about $10 \%$ medicinal plants of expected 7000 species of flowering plants [1]. Kavre district of Nepal is rich in biodiversity due to climatic variation and possesses varied medicinal plants. In developing countries, medicinal plants are potent sources of medicine to treat various diseases. The people (approximately 80\%) living in rural areas of underdeveloped countries still depend on medicinal plants for their basic health care [1]. Synthetic drugs are effective to cure various diseases, but in the long run, they show harmful side effects and they are expensive too. Hence, the drug development from the natural product is promising as plants show different bioactivity to cure ailments due to the presence of bioactive compounds.

Oxidative stress needs electron pairing for their stability and thus pair with biological macromolecules such as protein, DNA, lipids and even with healthy human cells, thereby gives rise to different diseases [2]. To scavenge these free radicals, synthetic antioxidants such as butylated hydroxytoluene, butylated hydroxyanisole, and tertiary butylated hydroquinone are being used. However, these commercially available antioxidants have side effects and are toxic in vivo. Hence, there is an increased in interest for safer antioxidants from natural sources to cure different diseases $[3,4]$. Glutathione is master antioxidant in human body have ability to neutralise and eliminate the free radical generated by oxidative stress [5].
Natural antioxidants, derived from plants, are secondary metabolites which scavenge the free radicals generated from the oxidation process in different cells and check different oxidative stress-related maladies. Natural antioxidants are less expensive having lower toxicity and side effects. In general, phenolic acids and flavonoids have been considered to show the bioactivity for scavenging free radicals. However, there might be other secondary metabolites which act as antioxidants. Natural antioxidants are less expensive having lower toxicity and side effects [6].

Nepal is enrich with several climatic conditions, geographical variations, and immense variety of plants with potential antidiabetic activities, but no effort has been made to seek more safe and efficient antioxidant and $\alpha$-amylase inhibitors from the natural sources so far. People of Nepal have been using medicinal plants for many years for treatment and cure of different diseases. Therefore, it is urgent to identify, explore and preserve the antioxidant with a quantitative estimation of flavonoid and phenolic content natural resources of Nepal. Hence, the present study mainly focused to evaluate the antioxidant potential of methanol extract of nine selected medicinal plants from Kavre district of Nepal, to examine for the antioxidant potential and to determine the total phenolic and flavonoid content in the plant extracts quantitatively.

\section{METHODS}

Collection and identification of plant samples

Different parts of nine medicinal plants were collected from the farmland of Panchkhal Municipality, Kavre, Nepal; the plants were 
collected in the summer of May/June 2017. The plants were identified by Prof. Dr. Mohan Sivakoti and Prof. Dr. Sangeeta Rajbhandari, Central Department of Botany, Tribhuvan University, Kathmandu, Nepal.

\section{Extract preparation}

Cleaned parts of plants were dried under shade at room temperature. Dried samples were chopped into pieces and then powdered using a mechanical grinder. Dried powder (100 g) was mixed separately in $400 \mathrm{~mL}$ methanol. The flasks were sealed tightly, and extraction was done for $72 \mathrm{~h}$ with occasional shaking. The obtained extracts were filtered and concentrated in a rotary evaporator. The yield of each fraction was determined and all the extracts were stored at $4{ }^{\circ} \mathrm{C}$ in a refrigerator until analyses.

\section{Preliminary phytochemical analysis}

The method employed for phytochemical screening was based on the standard protocol of Harbone et al. with some modifications [7].

\section{2,2-diphenyl-1-picrylhydrazyl radical scavenging assay}

Antioxidant capacity was measured by the use of free radical 2,2-diphenyl-1-picrylhydrazyl (DPPH). The ability of different plant extracts to scavenge DPPH free radical was performed by the standard protocol adopted by Jamuna et al. [8]. Ascorbic acid of the same concentrations as that of plant extract prepared was used as standard and its absorbance was measured at $517 \mathrm{~nm}$. Distilled water was used as a blank correction. The percentage of the DPPH free radical scavenging activity was calculated using the following equation:

$$
\text { radical scavenging }(\%)=\left[\frac{A_{0-} A_{s}}{A_{o}}\right] \times 100
$$

where,

$A_{0}=$ Absorbance of the control (DPPH solution + methanol)

$\mathrm{A}_{\mathrm{s}}=$ Absorbance of test sample

The $50 \%$ inhibitory concentration $\left(\mathrm{IC}_{50}\right.$ ) value was indicated as an effective concentration of the sample that required to scavenge $50 \%$ of the DPPH free radicals. $\mathrm{IC}_{50}$ values were calculated using the inhibition curve by plotting extract concentration versus the corresponding scavenging effect.

\section{Total phenolic content (TPC)}

The TPC of all selected plant extracts was estimated using FolinCiocalteu reagent using gallic acid as standard based on the oxidationreduction reaction. The total phenol content determination was performed with the help of the standard procedure given by Kim et al. (2007) with few modifications [6,9]. TPC content was expressed in milligram of gallic acid equivalent per gram of dry weight (mg GAE/g) of extract using the formula; $\mathrm{C}=\mathrm{cV} / \mathrm{M}$ where, $\mathrm{C}=\mathrm{TPC}$ compounds in $\mathrm{mg} / \mathrm{g}$, in gallic acid equivalent (GAE), $\mathrm{c}=$ concentration of gallic acid established from the calibration curve in $\mathrm{mg} / \mathrm{mL}, \mathrm{V}=$ Volume of extract in $\mathrm{mL}, \mathrm{M}=$ Weight of plant extract. The linear correlation coefficient $\left(R^{2}\right)$ value and regression equation were obtained from the gallic acid calibration curve. The regression equation was employed to calculate the concentration of each extract. Using the regression equation, the concentration of each extract was calculated. Thus, with the calculated value of the concentration of each extract, the TPC was calculated.

\section{Total flavonoid content (TFC)}

TFC of the selected plant extracts were determined by aluminum chloride colorimetric method using quercetin as standard with few modifications [10]. The TFC in plant extracts was expressed as milligram of quercetin equivalent per gram of dry weight (mg QE/g) of extract. TFC was expressed in milligram of quercetin equivalent per gram of dry weight (mg QE/g) of extract using the formula; $\mathrm{C}=\mathrm{cV} / \mathrm{M}$ where, $\mathrm{C}=\mathrm{TFC}$ compounds in $\mathrm{mg} / \mathrm{g}$, in quercetin equivalent $(\mathrm{QE}), \mathrm{c}=$ concentration of quercetin established from the calibration curve in $\mathrm{mg} / \mathrm{mL}, \mathrm{V}=$ Volume of extract in $\mathrm{mL}, \mathrm{M}=$ Weight of plant extract. The linear correlation coefficient $\left(R^{2}\right)$ value and regression equation were obtained from the quercetin calibration curve.

The crude methanol extract (7 g) of potent antioxidant Spondias pinnata was dissolved in $150 \mathrm{~mL}$ of distilled water; it was stirred well to make it dissolved completely. This was the mother solution, which was partitioned off successively by other solvents of different polarities, i.e., hexane, dichloromethane (DCM), and ethyl acetate. To the mother solution, $200 \mathrm{~mL}$ of hexane was added. It was then continuously shaken in separating funnel and let it stand until two layers were completely distinguishable. Hexane portion was then separated with an aqueous portion. The aqueous portion is further partitioned with DCM and ethyl acetate. Hence, finally hexane fraction, DCM fraction, and ethyl acetate fraction were obtained. In subsequent stages, each of the fractions was analyzed separately for the antioxidant property.

\section{RESULTS AND DISCUSSION}

\section{Qualitative phytochemical analysis}

The identification of major secondary metabolites of methanolic extracts was carried out to determine the presence or absence of the different phytoconstituents. The results were evaluated by visual inspection as a change in color or precipitation. Table 1 shows the presence or absence of phytoconstituents in nine different plant extracts.

All the nine selected plant extracts were found rich in secondary metabolites. Melia azedarach possessed all the phytochemicals which were undertaken for investigation. Hence, due to the presence of such secondary metabolites $M$. azedarach be a good source of such secondary metabolites [11]. S. pinnata and Psidium guajava were found good sources of coumarin as a secondary metabolite.

\section{2,2-diphenyl-1-picrylhydrazyl radical scavenging activity}

In vitro antioxidant study of an extract of different plants was performed using methanolic extracts. Fig. 1 showed the concentration dependent free radical scavenging activity of plant extracts. All the plant extracts showed the concentration-dependent increasing in radical scavenging capacity. Among nine medicinal plant extracts, three plants extracts, namely, Ageratina adenophora, Urtica dioica, and Achyranthes aspera were found least antioxidant and thus are the poor sources of natural antioxidant compounds. The greatest DPPH radical scavenging potency of with a minimum inhibitory concentration $\left(\mathrm{IC}_{50}\right.$ ) value was recorded for $S$. pinnata $(17.51 \pm 1.27 \mu \mathrm{g} / \mathrm{ml})$, followed by Bauhinia variegata $(26.55 \pm 2.61 \mu \mathrm{g} / \mathrm{ml})$, Melia azedarach $(62.04 \pm 1.55 \mu \mathrm{g} / \mathrm{ml})$, P. guajava $(70.91 \pm 2.61 \mu \mathrm{g} / \mathrm{ml})$, Curcuma longa $(83.50 \pm 6.42 \mu \mathrm{g} / \mathrm{ml})$, and Elaeocarpus angustifolius Blume $(104.23 \pm 3.58 \mu \mathrm{g} / \mathrm{ml})$. This assay is a simple and widely used and most acceptable technique to evaluate the antioxidant potency of plant extracts. The antioxidants are the chemical compounds of the plant which are capable of enacting the visually noticeable quenching of the stable purple-colored DPPH radical to the yellow-

Table 1: Phytochemical analysis of plants extracts

\begin{tabular}{lllllllllll}
\hline \multirow{2}{*}{ Compounds } & \multicolumn{9}{l}{ Sample } & \multicolumn{1}{l}{} \\
\cline { 2 - 9 } & SP & MA & PG & AD & UD & BV & AA & EAB & CL \\
\hline Reducing & - & + & - & - & - & + & + & + & + \\
sugars & & & & & & & & & \\
Polyphenols & + & + & + & - & - & + & + & + & - \\
Alkaloids & + & + & - & + & + & + & - & + & - \\
Glycosides & - & + & + & - & - & - & - & + & + \\
Quinones & + & + & + & + & + & + & + & + & - \\
Saponins & - & + & - & - & - & - & + & + & + \\
Coumarins & + & + & + & - & + & + & - & - & - \\
Flavonoids & + & + & + & - & - & + & - & - & + \\
Terpenoids & + & + & + & + & + & + & - & + & - \\
\hline
\end{tabular}

SP: Spondias pinnata, MA: Melia azedarach, AD: Ageratina adenophora,

UD: Urtica dioica, CL: Curcuma longa, BV: Bauhinia variegata, EAB: Elaeocarpus angustifolius Blume, AA: Achyranthes aspera, PG: Psidium guajava, - for absence and + for presence 


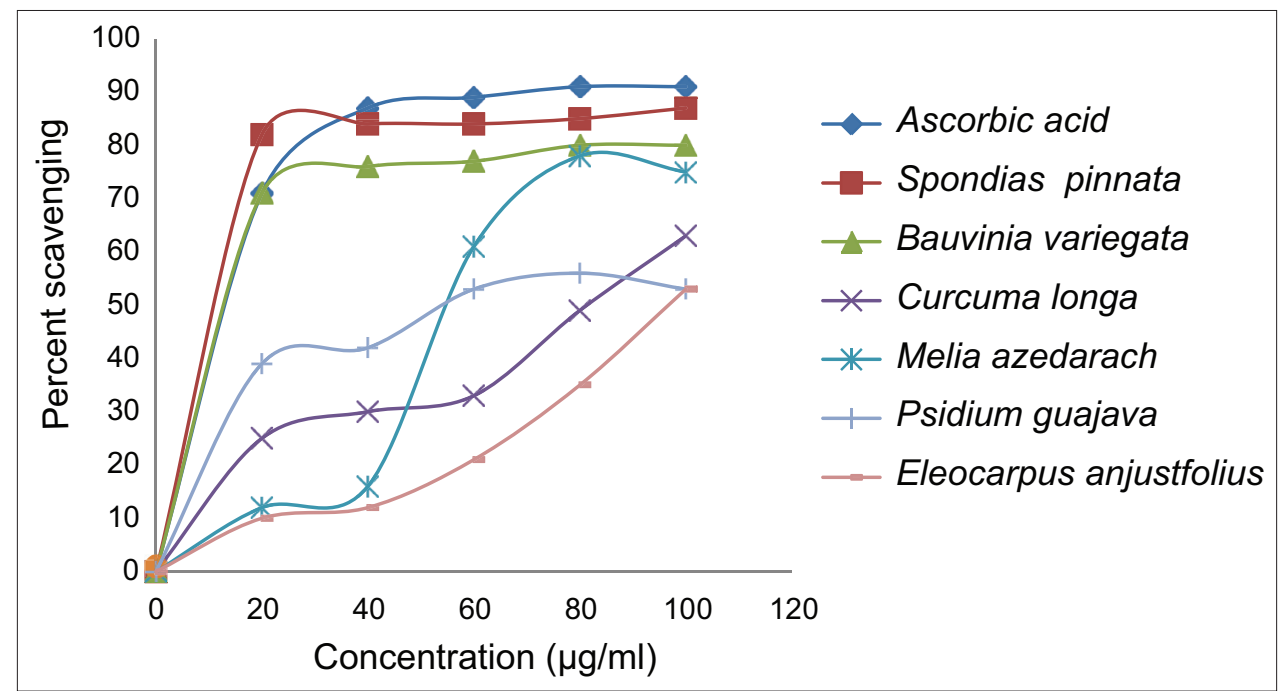

Fig. 1: Scavenging activity of ascorbic acid and selected medicinal plant extracts results expressed as the mean \pm standard deviation ( $\mathrm{n}=3$ ) at a concentration of $20,40,60,80$, and $100 \mu \mathrm{g} / \mathrm{ml}$

colored DPPH. The antioxidant potential of S. pinnata methanol extract was investigated in the search for new bioactive compounds from natural resources. Phytochemical analysis showed that the polyphenols were found in plant extract and act as reducing agents and antioxidants by the hydrogen donating property of their hydroxyl groups. These polyphenols are responsible for the observed antioxidant activity in this study.

The $\mathrm{IC}_{50}$ values of some plants which showed antioxidant property were calculated and tabulated in Table 2 . $\mathrm{IC}_{50}$ value is the concentration of ascorbic acid or plant extracts to scavenge $50 \%$ of DPPH free radicals.

The percent scavenging and $\mathrm{IC}_{50}$ of $S$. pinnata showed that the extract is the potent source of the natural antioxidant compound. Hence, it was further fractioned to examine the antioxidant property of different fractions in different solvents based on the polarity and individual fractions were subjected for an antioxidant activity where results are presented in the line graph given in Fig. 2.

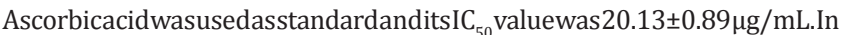
this study, S. pinnata and Bauhinia variegata showed significant antioxidant property with $\mathrm{IC}_{50} 17.51 \pm 1.27 \mu \mathrm{g} / \mathrm{mL}$ and $26.55 \pm 2.61 \mu \mathrm{g} / \mathrm{mL}$ respectively. The ethyl acetate fraction of $S$. pinnata showed the maximum scavenging (85.92 \pm 1.37 ) with $\mathrm{IC}_{50}$ value $46.95 \pm 1.17 \mu \mathrm{g} / \mathrm{mL}$. Table 3 showed the DCM and hexane fraction of $S$. pinnata has moderate inhibitory effect. The DCM and hexane fraction of S. Pinnata showed a moderate inhibitory effect. Similarly, the different fractions of $S$. pinnata showed the moderate antioxidant properties as well. S. spinnata and B. variegata showed the significant antioxidant property which is supported by previous studies where $\mathrm{IC}_{50}$ values for scavenging were $24.48 \pm 2.31 \mu \mathrm{g} / \mathrm{mL}$ and $6.48 \pm 0.08 \mu \mathrm{g} / \mathrm{mL}$ for $S$. spinnata and B. variegata, respectively $[2,12]$. Previous studies showed that DPPH free radical scavenging activity of different fractions of $S$. pinnata was found to be concentration-dependent, i.e., scavenging property increases with the increase in concentration and the finding of the present study is supported by the recent result not only in S. pinnata but also in rest of the plant extracts. Sharma et al. and Manik et al. concluded the fact about the potentiality of B. variegata and $S$. spinnata to act as a natural antioxidants $[12,13]$. The antioxidant activity of Lepidium sativum ethanol extract showed $\mathrm{IC}_{50}$ values of $162.4 \pm 2.3$, $35.29 \pm 1.02,187.12 \pm 3.4$, and $119.32 \pm 1.5 \mu \mathrm{g} / \mathrm{ml}$ in terms of DPPH which is comparable to the antioxidant activity showed by the plant extracts in the present study [14].

TPC

A calibration curve was constructed using gallic acid as standard. The TPC in each plant extracts was estimated with the help of calibration curve. The result is shown in Table 4.

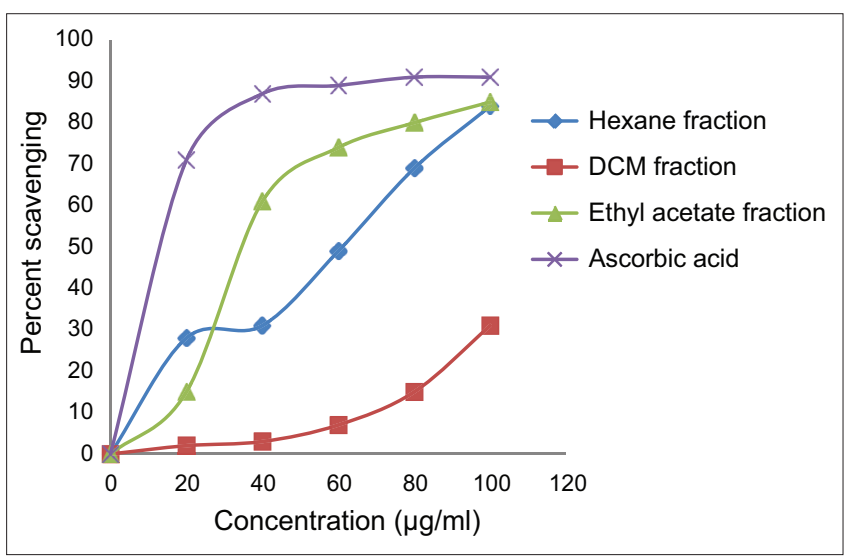

Fig. 2: Percent scavenging of different fractions of Spondias pinnata

Table 2: Half maximal inhibitory concentration values for antioxidant activity of different plants extracts

\begin{tabular}{lll}
\hline $\begin{array}{l}\text { Serial } \\
\text { number }\end{array}$ & $\begin{array}{l}\text { Name of plant } \\
\text { extracts/standard }\end{array}$ & $\begin{array}{l}\mathbf{I C}_{\mathbf{5 0}}(\boldsymbol{\mu g} / \mathbf{m L}), \\
\text { mean } \pm \text { SD }\end{array}$ \\
\hline 1. & Ascorbic acid (standard) & $20.13 \pm 0.89$ \\
2. & SP & $17.51 \pm 1.27$ \\
3. & BV & $26.55 \pm 2.61$ \\
4. & CL & $83.50 \pm 6.42$ \\
5. & MA & $62.04 \pm 1.55$ \\
6. & EAB & $104.23 \pm 3.58$ \\
7. & PG & $70.91 \pm 2.61$ \\
\hline
\end{tabular}

SP: Spondias pinnata, BV: Bauhinia variegata, CL: Curcuma longa, MA: Melia azedarach, EAB: Elaeocarpus angustifolius Blume, PG: Psidium guajava,

SD: Standard deviation, $\mathrm{IC}_{50}$ : Half maximal inhibitory concentration

Table 3: $\mathrm{IC}_{50}$ values of different fractions of methanol extract of Spondias pinnata

\begin{tabular}{ll}
\hline Name of plant samples/standard & IC $_{50}(\boldsymbol{\mu g} / \mathbf{m L})$, mean \pm SD \\
\hline Ascorbic acid (standard) & $20.13 \pm 0.89$ \\
Hexane fraction & $57.31 \pm 2.25$ \\
DCM fraction & $185.54 \pm 2.63$ \\
Ethyl acetate fraction & $46.95 \pm 1.17$ \\
\hline
\end{tabular}

DCM: Dichloromethane, SD: Standard deviation, $\mathrm{IC}_{50}$ : Half maximal inhibitory concentration 
Table 4: Total phenolic content of different plant extracts

\begin{tabular}{|c|c|c|c|c|c|c|c|}
\hline \multirow[t]{2}{*}{ Name of plants } & \multicolumn{3}{|c|}{ Absorbance } & \multicolumn{4}{|c|}{ TPC (mg GAE/g) } \\
\hline & A1 & $\mathbf{A 2}$ & A3 & C1 & $\mathrm{C} 2$ & C3 & Mean \pm SD \\
\hline SP & 0.742 & 0.761 & 0.744 & 47.44 & 49.67 & 47.67 & $48.26 \pm 1.23$ \\
\hline Eleocarpus anjustifolius & 0.402 & 0.351 & 0.39 & 9.67 & 4.00 & 8.33 & $7.33 \pm 2.96$ \\
\hline $\mathrm{BV}$ & 0.620 & 0.572 & 0.630 & 33.89 & 28.56 & 35.00 & $32.48 \pm 3.44$ \\
\hline MA & 0.461 & 0.410 & 0.451 & 16.22 & 10.56 & 15.11 & $13.96 \pm 2.99$ \\
\hline AA & 0.401 & 0.350 & 0.373 & 9.56 & 3.89 & 6.44 & $6.63 \pm 2.84$ \\
\hline PG & 0.55 & 0.673 & 0.662 & 26.11 & 39.78 & 33.89 & $33.26 \pm 6.86$ \\
\hline
\end{tabular}

GAE: Gallic acid equivalent, SD: Standard deviation, SP: Spondias pinnata, BV: Bauhinia variegata, CL: Curcuma longa, MA: Melia azedarach, PG: Psidium guajava, AA: Achyranthes aspera, TPC: Total phenolic content

Table 5: Total flavonoid content of different plant extracts

\begin{tabular}{|c|c|c|c|c|c|c|c|}
\hline \multirow[t]{2}{*}{ Name of plants } & \multicolumn{3}{|c|}{ Absorbance } & \multicolumn{4}{|c|}{ TFC (mg QE/g) } \\
\hline & $\mathbf{A 1}$ & A2 & A3 & $\mathrm{C1}$ & $\mathrm{C} 2$ & $\mathrm{C} 3$ & Mean $\pm S D$ \\
\hline SP & 0.123 & 0.133 & 0.129 & 8.39 & 10.00 & 9.35 & $9.24 \pm 0.089$ \\
\hline CL & 0.199 & 0.222 & 0.215 & 20.65 & 24.35 & 23.23 & $22.74 \pm 1.89$ \\
\hline BV & 0.106 & 0.099 & 0.109 & 5.65 & 4.52 & 6.13 & $5.53 \pm 0.82$ \\
\hline MA & 0.333 & 0.315 & 0.329 & 42.26 & 39.35 & 41.61 & $41.07 \pm 1.53$ \\
\hline $\mathrm{AA}$ & 0.086 & 0.093 & 0.081 & 2.42 & 3.55 & 1.61 & $2.52 \pm 0.97$ \\
\hline PG & 0.132 & 0.139 & 0.145 & 9.84 & 10.97 & 11.94 & $10.92 \pm 1.05$ \\
\hline
\end{tabular}

SP: Spondias pinnata, BV: Bauhinia variegata, CL: Curcuma longa, MA: Melia azedarach, PG: Psidium guajava, AA: Achyranthes aspera, SD: Standard deviation,

QE: Quercetin equivalent, TFC: Total flavonoid content

The TPC of extract of all selected medicinal plants showed varied results ranging from $6.63 \pm 2.84$ to $48.26 \pm 1.23 \mathrm{mg} \mathrm{GAE} / \mathrm{g}$ in Achyranthes aspera and Spondias pinnata, respectively. The total phenol content of the rest of the plant extract lied between these two extremes. The extract of Ageratina adenophora and $U$. dioica showed poor antioxidant property with not significance TPC. Similarly, Achyranthes aspera showed poor antioxidant property was also a moderate source of TPC. On the other hand, those plant extracts (S. pinnata and B. variegata) which showed potent antioxidant property also have appreciable TPC. The present findings agree with the view that DPPH scavenging activity and phenolic content of the plant extract are related as an antioxidant property of plant extract is directly correlated with its phenolic content [12]. A high correlation between antioxidant capacities and their TPCs indicated that phenolic compounds were a major contributor to antioxidant activity of these plant extracts.

TFC

TFC of the selected plants' extracts was determined by aluminum chloride colorimetric method taking quercetin as standard. The absorbance of quercetin (standard) was recorded from the spectrophotometer and the result is tabulated in Table 5.

The TFC of different selected medicinal plant extracts was found and the results revealed that the TFC varied from $2.52 \pm 0.97 \mathrm{mg} \mathrm{QE} / \mathrm{g}$ in Achyranthes aspera to $41.07 \pm 1.53 \mathrm{mg} \mathrm{QE} / \mathrm{g}$ in Melia azedarach. All the remaining plants extract showed the TFC in between two extremes; however, U. dioica, Elaeocarpus angustifolius Blume, and Ageratina adenophora are the moderate sources of TFC. Sharma et al. and Hazra et al. have suggested that greater flavonoid content of plant extract could be directly correlated with higher free radical scavenging property [12]. The present study showed that the antioxidant activity is not only due to the presence of flavonoid and phenolic compounds but also the presence of some other organic compounds that act as reducing agents.

\section{CONCLUSIONS}

The DPPH radical scavenging activities and subsequently the $\mathrm{IC}_{50}$ values of methanolic extracts of the selected plants showed a varied degree of antioxidant property; of which, S. pinnata showed appreciable percent scavenging followed by $B$. variegata. The highest percent scavenging showed by $S$. pinnata has $\mathrm{IC}_{50}$ value $17.51 \pm 1.27 \mu \mathrm{g} / \mathrm{ml}$ while the standard, ascorbic acid has $20.13 \pm 0.89 \mu \mathrm{g} / \mathrm{ml}$. Further, the ethyl acetate fraction of $S$. pinnata showed the maximum scavenging (85.92 \pm 1.37 ) with $\mathrm{IC}_{50}$ value $46.95 \pm 1.17 \mu \mathrm{g} / \mathrm{ml}$. The greater antioxidant property on them is credited to bioactive secondary metabolites especially phenols but not flavonoids. Hence, these plants could be the potential substitutes of synthetic antioxidants. Although, some medicinal plants showed a significant antioxidant property, they cannot directly be referred for pharmaceutical usage. Further extensive phytochemical and pharmacological investigation must be done to explore the mechanism of action and to isolate and characterize lead compounds that are responsible for pharmacological properties. This study demonstrates that these medicinal plants could be a potential source of natural antioxidants. Further studies need to be conducted to identify alkaloids and phenolic compounds that are correlated with the antioxidant activity of $S$. pinnata as well as their synergistic interactions.

\section{Statistics}

All the analyses were carried out in triplicate, and the results are expressed as mean $\pm \mathrm{SD}$.

\section{ACKNOWLEDGMENTS}

Authors are thankful to the Central Department of Chemistry, Tribhuvan University for laboratory facilities and providing some chemicals. We are grateful to Prof. Dr. Mohan Sivakoti and Prof. Dr. Sangeeta Rajbhandari, Central Department of Botany, Tribhuvan University, Kathmandu, Nepal, for identification of plants.

\section{AUTHORS' CONTRIBUTIONS}

Dr. Khaga Raj Sharma analyzed the data and wrote the manuscript, whereas Rupak Kharel carried out the laboratory work. Both the authors read and approved the final manuscript.

\section{REFERENCES}

1. Muhammad A, Rahman MS, Kabir AH, Kabir S, Hossain MK. Antibacterial and cytotoxic activities of Spondias pinnata (Linn. f.) Kurz fruit extract. Indian J Nat Prod Resour 2011;2:265-7.

2. Hazra B, Biswas S, Mandal N. Antioxidant and free radical scavenging activity of Spondias pinnata. BMC Complement Altern Med 2008;8:63.

3. Ramamoorthy PK, Bono A. Antioxidant activity, total phenolic and 
flavonoid content of Morinda citrifolia fruits extracts from various extraction process. J Eng Sci Technol 2007;2:70-80

4. Patel VR, Patel PR, Kajal S. Antioxidant activity of some selected medicinal plants in Western region of India. Adv Biol Res 2010;4:23-6.

5. Nagarathna PK, Kashikant Y, Lou DM, Bhutia GT. Screening of anticancer and anti-oxidant activity of leaves of Annona reticulata on EAC induced solid tumor. Int J Pharm Sci Res 2019;10:4868-80.

6. Kim MK, Lee HS, Kim EJ, Won NH, Chi YM, Kim BC, et al. Protective effect of aqueous extract of Perilla frutescens on tert-butyl hydroperoxide-induced oxidative hepatotoxicity in rats. Food Chem Toxicol 2007; 45:1738-44.

7. Harbone JB. Phytochemical Methods: A Guide to Modern Techniques of Plant Analysis. London, New York: Champman and Hall. Ltd.; 1973. p. 279.

8. Jamuna S, Paulsamy S, Karthika K. Screening of in vitro antioxidant activity of methanolic leaf and root extracts of Hypochaeris radicata $\mathrm{L}$. (Asteraceae). J Appl Pharm Sci 2012;2:149-54.

9. Gajula D, Verghese M, Boateng J, Walker LT, Shackelford L,
Mentreddy SR, et al. Determination of total phenolics, flavonoids and antioxidant and chemopreventive potential of Basil(Ocimum basilicum $\mathrm{L}$. and Ocimum tenuiflorum L.). Int J Cancer Res 2009;5:130-43.

10. Pallab K, Tapan B, Tapas P, Ramen K. Estimation of total flavonoid content (TFC) and antioxidant activities of methanolic whole plant extract of Biophytum sensitivum Linn. J Drug Deliv Ther 2013;3:33-7.

11. Pokhrel B, Raut S, Rijal S. Phytochemical screening, antimicrobial and antioxidant activity of Melia azedarach leaves in methanol. World J Pharm Pharm Sci 2015;4:1562-75.

12. Sharma KR, Kalauni SK, Awale S. Phytotoxic and antimicrobial activities of methanolic extract of Bauhinia variegata barks. J Inst Sci Technol 2015;20:37-41.

13. Manik MK, Islam SM, Wahid MA, Morshed MM, Kamal S, Islam MS, et al. Investigation of in vitro antioxidant, antimicrobial and thrombolytic activity of the exocarp of Spondias pinnata (Anacardiaceae). Can Chem Trans 2013;1:191-201.

14. Snafi AE. Chemical constituents and pharmacological effects of Lepidium sativum-a review. Int J Curr Pharm Res 2019;11:1-10. 